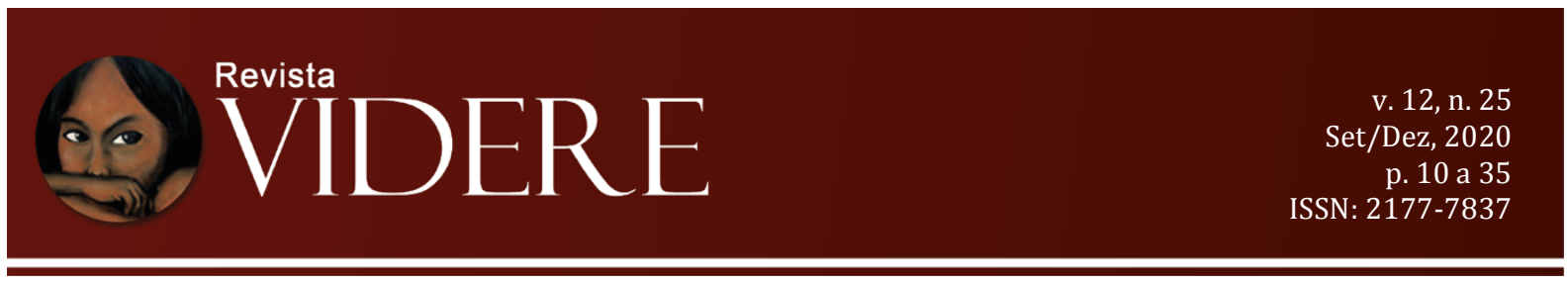

\title{
O IUS CONSTITUCIONALE COMMUNE E SUA CONFORMAÇÃO NA CORTE INTERAMERICANA DE DIREITOS HUMANOS: ALGUNS ASPECTOS TEÓRICOS
}

\author{
THE IUS CONSTITUCIONALE COMMUNE AND ITS CONFORMATION IN THE \\ INTER-AMERICAN COURT OF HUMAN RIGHTS: SOME THEORETICAL ASPECTS
}

\author{
EL IUS CONSTITUTIONALE COMMUNE Y SU CONFORMACIÓN EN LA CORTE \\ INTERAMERICANA DE DERECHOS HUMANOS: ALGUNOS ASPECTOS TEÓRICOS
}

Mônia Clarissa Hennig Leal

Pós-Doutora em Direito pela Ruprecht-Karls Universität Heidelberg (Alemanha). Professora e Coordenadora adjunta do Programa de Pós-Graduação em Direito - Mestrado e Doutorado da Universidade de Santa Cruz do Sul - UNISC. moniah@unisc.br OrcidID: https://orcid.org/0000-0002-3446-1302

\begin{abstract}
Eliziane Fardin de Vargas Mestranda no Programa de Pós-Graduação Stricto Sensu em Direitos Sociais e Políticas Públicas da Universidade de Santa Cruz do Sul - UNISC. elizianefvargas@mx2.unisc.br OrcidID: https://orcid.org/0000-0002-3192-659X
\end{abstract}

\begin{abstract}
Resumo: O artigo busca responder ao seguinte questionamento: qual o conceito de ius constitucionale commune na América Latina e qual sua conformação nas decisões da Corte Interamericana de Direito Humanos? Para responder ao questionamento pretende-se discutir inicialmente o conceito de ius constitucionale commune na América Latina, explanar a fundamentalidade do diálogo entre os sistemas nacionais e internacionais para uma proteção mais ampla aos direitos humanos e como isso contribui para o desenvolvimento do ius constitucionale commune na região, para posteriormente analisar a sua conformação teórica nas decisões da Corte Interamericana de Direitos Humanos. Para atingir esse objetivo, utilizase o método dedutivo, empregando a técnica de pesquisa bibliográfica e documental. Concluiu-se que o desenvolvimento do ius constitucionale commune na região latinoamericana decorre de diversos fatores - aberturas constitucionais, integração dos Estados ao Sistema Interamericano, reconhecimento da jurisdição da Corte IDH, exercício do controle de convencionalidade, dos diálogos jurisdicionais, entre outros -, ao passo que sua conformação teórica tem emergido a partir das construções jurisprudenciais da Corte IDH.
\end{abstract}

Palavras-chave: Ius Constitucionale Commune. constitucionalismo transformador. Jurisprudência interamericana. Corte Interamericana de Direitos Humanos. 
Abstract: The article seeks to answer the following question: what is the concept of ius constitutionale commune in Latin America and what is its theoretical conformation by the Inter-American Court of Human Rights? To answer the question, it was intended to discuss the concept of ius constitutionale commune in Latin America, explain the fundamentality of the dialogue between national and international systems for a broader protection of human rights and thereby contributing to the development of ius constitutionale commune in region, to subsequently analyze the theoretical conformation of the ius constitucionale commune by the Inter-American Court of Human Rights. To achieve this objective it's used the deductive method through the technique of bibliographic and documentary research. It was concluded that the development of the ius constitucionale commune in the Latin American region results from several factors - constitutional openings, integration of States into the Inter-American System, recognition of the jurisdiction of the Inter-American Court, exercise of conventionality control, jurisdictional dialogues, among others -, while its theoretical conformation has emerged from the jurisprudential constructions of the Inter-American Court.

Keywords: Ius Constitucionale Commune. transformative constitutionalism. inter-american jurisprudence. Inter-American Court of Human Rights.

Resumen: El artículo busca investigar cuál es el concepto de ius constitutionale commune en la América Latina y cuál su conformación en las decisiones de la Corte Interamericana de Derechos Humanos. Para responder la problemática, se descutirá inicialmente el concepto de ius constitucionale commune em la América Latina y se explicará la fundamentalidad del diálogo entre los sistemas nacionales e internacionales para una protección más amplia de los derechos humanos y como esto contribuye com el desarrollo del ius constitucionale commune en la región, para, entonces, analizar su conformación teórica en las decisiones de la Corte Interamericana de Derechos Humanos. Para lograr este objetivo se utiliza el método deductivo $\mathrm{y}$, la técnica de investigación bibliográfica y documental. Se concluyó que el desarrollo del ius constitutionale commune en la región latinoamericana resulta de varios factores - aperturas constitucionales, integración de los Estados em el Sistema Interamericano, reconocimiento de la jurisdicción de la Corte Interamericana, ejercicio del control de convencionalidad, de los diálogos jurisdiccionales, entre otros -, mientras que su conformación teórica ha sido plateada a partir de las construcciones jurisprudenciales de la Corte Interamericana.

Palabras clave: Ius Constitutionale Commune. constitucionalismo transformador. jurisprudencia interamericana; Corte Interamericana de Derechos Humanos.

\section{Introdução}

O tema a ser abordado merece destaque em razão da valiosa contribuição que o ius constitucionale commune busca agregar à região latino-americana, objetivando a efetivação do Estado de Direito, da democracia e dos direitos humanos em uma região marcada por um histórico de discriminação, desigualdade social e regimes autoritários.

Para melhor compreender essa ideia de um direito comum, é essencial o conhecimento do conceito formador dessa teoria. É diante do debate teórico quanto à conceituação desse fenômeno que se desenvolve a problemática a ser trabalhada ao longo 
deste artigo, calcada no seguinte questionamento: no que consiste o conceito de ius constitucionale commune e como se dá sua conformação nas decisões da Corte Interamericana de Direitos Humanos?

Objetivando responder ao questionamento levantado, inicialmente será abordado o conceito de ius constitucionale commune na América Latina e o seu desenvolvimento a partir do constitucionalismo transformador. Em seguida, abordar-se-á a importância do diálogo entre os ordenamentos jurídicos nacionais e o Sistema Interamericano, visto que o entrelaçamento dessas ordens jurídicas possibilita um desenvolvimento mais efetivo de um direito constitucional comum interamericano capaz de fornecer maior resguardo aos direitos humanos. Por fim, o trabalho analisará como se dá a sua conformação pela jurisprudência da Corte Interamericana de Direitos Humanos, através da sua função contenciosa.

\section{Introdução ao desenvolvimento da teoria do ius constitucionale commune na América}

\section{Latina}

Nos últimos 40 anos, a Convenção Americana sobre Direitos Humanos ${ }^{1}$ vem sendo considerada como a base para o desenvolvimento do constitucionalismo transformador latinoamericano. Fatores como a violência, desigualdade, exclusão social e a deficiência das instituições latino-americanas destinam ao constitucionalismo transformador a difícil tarefa de realizar a atividade interpretativa das normas constitucionais e aplicá-las de maneira a desencadear uma profunda alteração social com intuito de atingir objetivos constitucionais específicos (BOGDANDY, 2019, p. 233).

A ideia de um direito constitucional comum na América Latina é construída a partir dos direitos humanos elencados na Convenção Americana, no protocolo de San Salvador, nos demais tratados e normas de direitos humanos, bem como pela jurisprudência da Corte Interamericana, sendo por meio desse cenário que os Estados-parte do Sistema Regional dialogam e partilham princípios, normas e valores instituidores da dignidade humana. Portanto, o eixo normativo e jurisdicional do ius constitucionale commune latino-americano está no Sistema Interamericano de Direitos Humanos, o qual tem a precípua finalidade de promover o resguardo dos direitos humanos na região da América Latina, “influenciando não somente as decisões políticas e jurídicas no âmbito interno dos Estados, como também

\footnotetext{
${ }^{1} \mathrm{Na}$ Conferência Especializada Interamericana sobre Direitos Humanos, realizada em São José, na Costa Rica, foi adotada e posta à assinatura em 22 de novembro de 1969 a Convenção Americana de Direitos Humanos (CADH) ou Pacto de São José da Costa Rica. Entrando em vigor em 18 de julho de 1978, data em que obteve 11 ratificações, assim atendendo ao disposto no artigo 74.2 da Convenção Americana. (RAMOS, 2020, n.p) 
compelindo os Estados a adotarem medidas administrativas, legislativas e jurisdicionais necessárias à efetividade dos direitos humanos" (RESENDE, 2019, p. 79). Dessa maneira, através da interação e troca de experiência entre o direito constitucional dos Estados e do direito interamericano dos direitos humanos, realizar a construção e determinação de parâmetros constitucionais mínimos de regras, valores e princípios com o desígnio de salvaguardar os direitos humanos (RESENDE, 2019, p. 80).

Dessa forma, o movimento do constitucionalismo transformador vislumbra, através da supraestatalidade, do pluralismo dialógico dos ordenamentos internacionais e nacionais e da atuação judicial, a alteração da realidade regional marcada por violações e desigualdade. É a partir desse bloco de ideias que o ius constitucionale commune na América Latina é pensado, sendo construído por "um corpo de direito comum latino-americano que expressa uma construção regional de standards em matéria de direitos humanos, democracia e estado de direito" (MELLO, 2019, p. 257). Assim, ressalta-se que a elaboração desses standards é construída com base na Convenção Americana de Direitos Humanos, bem como nos demais pactos internacionais, nas constituições nacionais e nos posicionamentos explicitados pelas cortes nacionais e pelo Sistema Interamericano de Direitos Humanos em relação ao tema (MELLO, 2019, p. 257).

Desse modo, as instituições que compõem o Sistema Interamericano vêm recebendo da Convenção Americana de Direitos Humanos um mandato, advindo tanto das disposições explicitadas nas sentenças da Corte Interamericana de Direitos Humanos - as quais atingem as partes envolvidas no litígio (res judicata), como também transcende seus efeitos vinculando os demais Estados-partes a observarem suas interpretações (res interpretata) -, como da dimensão objetiva dos direitos fundamentais, ao passo que impõe a todos os Estados-partes o dever de readequação dos seus ditames internos de acordo com os parâmetros da Convenção Americana e das legítimas interpretações dessa pela Corte Interamericana de Direitos Humanos (MAC-GREGOR, 2013, p. 655), isso tudo com o escopo de desenvolver esse constitucionalismo transformador na América Latina. Tal mandato fornece, por sua vez, o respaldo jurídico necessário para a constituição de uma jurisprudência em matéria de direitos humanos que trate de problemas típicos da região latino-americana (BOGDANDY, 2019, p. 234):

El carácter evolutivo de la jurisprudencia interamericana ha permitido interpretar el contenido obligacional derivado del artículo $2^{\circ}$ de la Convención Americana de "adoptar disposiciones de derecho interno" sean "medidas legislativas o de otro carácter que fueren necesarias para hacer 
efectivos" los derechos y libertades. Esto ha motivado una jurisprudencia interamericana amplia sobre diversas temáticas (FERRER MAC-GREGOR, 2013, p. 664).

Assim, têm-se os elementos para a conformação de uma espécie de ius constitucionale commune na América Latina, sendo que essa jurisprudência proveniente da Corte IDH não apenas informa como inclusive orienta a atuação dos juízes regionais, conformando assim um direito comum dos direitos humanos, o qual provoca mudanças concretas na vida dos indivíduos (BOGDANDY, 2019, p. 234-235). Objetivando mudanças profundas $^{2}$, idealizar ações capazes de desenvolver um constitucionalismo transformador das desigualdades sociais e políticas que assolam os países da região latino-americana é o enfoque do ius constitucionale commune latino-americano (JARAMILLO, 2017, p. 580).

Essas mudanças almejadas pelo constitucionalismo transformador podem se desenvolver, dentre outros aspectos, através da atuação do Sistema Interamericano de Direitos Humanos como um todo, mais especificamente a partir da jurisprudência e das decisões proferidas pela Corte Interamericana de Direitos Humanos. A possibilidade de promover mudanças estruturais está prevista no corpo da Convenção Americana sobre Direitos Humanos, mais especificamente nos artigos 67 e 68.1. Esses artigos, ao preverem a não sujeição das decisões proferidas pela Corte Interamericana de Direitos Humanos a recurso, e portanto, sendo essas definitivas e finais - evidenciando-se, dessa maneira, a eficácia vinculante das decisões proferidas pela Corte Interamericana de Direitos Humanos vinculam os Estados-partes da Convenção Americana que, diante da declaração de sua responsabilidade internacional, ficam estes obrigados ao cumprimento de medidas reparatórias, as quais, por sua vez, apresentam "um caráter binário, constituído em medidas de reparação individual (restituição, compensação e satisfação) e medidas destinadas a modificar as causas estruturais que permitiram as violações (obrigação de não-repetição)." (LEAL; ALVES, 2015, p. 290). Deste modo, com a previsão do artigo 67, o qual estabelece a "incontestabilidade" da decisão proferida pela Corte Interamericana, essa adquire "autoridad de cosa juzgada internacional", concedendo força ao ato jurisdicional que põe fim ao processo internacional (MAC-GREGOR, 2013, p. 656).

\footnotetext{
2 A Corte Interamericana de Direitos Humanos tem utilizado de ferramentas capazes de não só reparar e indenizar as partes diretamente afetadas com a violação, mas tem buscado igualmente, através das sentenças estruturantes, uma atuação com escopo preventivo e de não-repetição de violações, de modo que os efeitos inter partes da sentença transcenda-se aos demais Estados-partes, para que os direitos humanos sejam promovidos e novas violações idênticas às combatidas na decisão não voltem a ocorrer. (LEAL; ALVES, 2015, p. 288) 
Para Ferrer Mac-Gregor (2013, p. 656-657), essa sentença comporta efeitos em duas dimensões: uma subjetiva, que diz respeito à obrigatoriedade do Estado em executar a condenação estabelecida na sentença interamericana, dando a parte afetada o cumprimento rápido e efetivo da obrigação nela prevista; e outra objetiva, a qual tem efeitos para com todos os Estados-parte da Convenção Americana, conformando, assim, a eficácia erga omnes, visto que:

en la medida en que todas las autoridades nacionales quedan vinculadas a la efectividad convencional $\mathrm{y}$, consecuentemente, al criterio interpretativo establecido por la Corte IDH, en tanto estándar mínimo de efectividad de la norma convencional, derivada de la obligación de los Estados de respeto, garantía y adecuación (normativa e interpretativa) que establecen los artículos $1^{\circ}$ y $2^{\circ}$ de la Convención Americana (FERRER MAC-GREGOR, 2013, p. 656-657).

Assim, conforma-se uma eficácia erga omnes em relação aos Estados-parte da Convenção, vinculando-os a cumprir os standards interpretativos desenvolvidos pela Corte Interamericana de Direitos Humanos. Desse modo, possuem as decisões da Corte IDH um duplo efeito, primeiramente possui efeito subjetivo (res judicata), que atinge de maneira direta e imediata as partes do caso, e também um efeito objetivo (res interpretata), o qual conforma o "standard interpretativo mínimo da Convenção Americana, componente do corpus iuris interamericano, com dever de observância prima facie pelos demais Estados (arts. 1.1., 2 e 62.1 do Pacto de San José)” (MELLO, 2019, p. 259).

Há, portanto, uma obrigatoriedade em relação aos Estados-parte que os vincula a aplicar não apenas a norma convencional, como também a "“norma convencional interpretada' (res interpretata); es decir, el criterio interpretativo que como estándar mínimo aplicó el Tribunal Interamericano al Pacto de San José y, en general al corpus juris interamericano" (FERRER MAC-GREGOR, 2013, p. 662). Porém, essa eficácia interpretativa tem caráter relativo, podendo as autoridades nacionais expandi-la, ampliando sua interpretação, e até mesmo deixar de adotar a interpretação fixada pela Corte Interamericana de Direitos Humanos, quando em âmbito interno ou internacional houver uma interpretação mais favorável, devendo então optar-se pela interpretação que mais proteja o direito em questão, incorporando-se assim, uma interpretação evolutiva e mais favorável ao ser humano decorrente do princípio "pro homine” ou "pro persona” (MAC-GREGOR, 2013, p. 676). 
Em relação às medidas trazidas na ocasião da sentença proferida pela Corte Interamericana de Direitos Humanos, importa destacar que o conceito de reparação presente nessas decisões é lato, abarcando não apenas a obrigação do Estado em indenizar pecuniariamente a vítima ou seus familiares, como também impõe medidas com o escopo de garantir uma prevenção e não-repetição das violações ocorridas. Assim, essas sentenças geram a "promoção das responsabilidades internas pela violação e as chamadas "medidas de não-repetição", que podem envolver alterações de políticas públicas, de legislação interna, e de jurisprudência pacificada até mesmo da Corte Suprema de um país” (BERNARDES, 2011, p. 148).

Diante disso, é essencial resgatar a ideia de que o dever de proteção estatal advém da dimensão objetiva dos direitos fundamentais. Leal e Azevedo (2016, p. 447) ressaltam que a dimensão objetiva dos direitos fundamentais trabalha com a ideia de proteção por parte do estado, a qual "impõe um dever de adequação da ordem jurídica no sentido de sua realização, a partir do momento em que são compreendidos como "diretivas e impulsos" vinculantes para todos os Poderes, que devem atuar em plena consonância com os direitos fundamentais.”.

Esse "dever de proteção" compreende não apenas a proteção da pessoa contra arbitrariedades do Estado, como também reconhece como dever do Estado a proteção do indivíduo contra violações provenientes de terceiros. Assim, o fenômeno do "dever de proteção" (Schutzpflicht), exige, simultaneamente, uma ação estatal com o escopo de protetorar as liberdades individuais, ou direitos de defesa da pessoa conta o estado, como também "procura proteger o indivíduo de ameaças oriundas não do Estado, "mas de atores privados, forças sociais ou mesmo outros desenvolvimentos controláveis pela ação estatal” (LEAL; AZEREDO, 2016, p. 448).

Portanto, há na dimensão objetiva dos direitos fundamentais não só um dever de abstenção por parte do Estado em cometer violações de direitos, como também a obrigação de fornecer efetiva proteção aos indivíduos, garantindo subsídios mínimos para que esses possam exercer seus direitos sem nenhum óbice ou repressão (SARMENTO, 2004, p. 135). Assim, nas decisões da Corte Interamericana de Direitos Humanos, a imposição do dever do Estado infrator em adotar medidas preventivas e de não-repetição corresponde à dimensão objetiva dos direitos humanos e fundamentais, de modo que o Estado fica obrigado a fornecer para toda a sociedade a proteção capaz de prevenir novas violações como as que ensejaram a condenação.

Diante dessa dimensão objetiva dos direitos humanos resguardados pelos tratados internacionais, estes consagram padrões comuns de proteção, contexto em que o ius commune 
expressa "um piso normativo mínimo de salvaguarda dos direitos humanos comum a todos os Estados integrantes do Sistema Interamericano de Direitos Humanos.”, onde a recognição da existência de um direito constitucional latino-americano demonstra a subsistência de "valores, regras e princípios de natureza constitucional concomitantemente compartilhados entre os Estados, que limitam a atuação dos entes estatais” (RESENDE, 2019, p. 78).

Com igual escopo, qual seja, o de prevenir que se repitam violações por parte dos Estados, é que o ICCAL almeja "contribuir para a construção de estratégias de resiliência em momentos de ameaça de retrocesso, ajudando a proteger as conquistas já alcançadas e os standards já consolidados.” (MELLO, 2019. p. 278). Assim, no momento em que o Estado adota junto ao Sistema Interamericano a responsabilidade de cumprir obrigações inerentes a este compromisso internacional, adquire o ICCAL a função de estabelecer uma rede de proteção contra eventuais retrocessos (MELLO, 2019. p. 275-276).

Grande parte dos estudos desenvolvidos sobre o ICCAL ocorreu graças às pesquisas elaboradas pelo Instituto Max Planck de Direito Público Internacional e Comparado de Heidelberg. O instituto alemão vem promovendo desde 2004 o Colóquio Ibero-americano, sendo comandado, desde o ano de 2006, pela pesquisadora especialista em estudos latinoamericanos Mariela Morales Antoniazzi. As sessões do Colóquio - até o momento contabilizando cerca de 123 sessões - são o palco de trocas e comparações de ideias de pesquisadores e participantes, em que várias temáticas são abordadas. É possível afirmar que o constitucionalismo transformador da América Latina adquiriu expressiva atenção, visto que o evento "promoveu a análise jurídica desse desafio, com uma abordagem contrastiva e internacionalista, o que provoca uma série de inovações. Esse enfoque jurídico holístico é cada vez mais conhecido como Ius Constitutionale Commune na América Latina (ICCAL)" (BOGDANDY, 2015, p. 15-16).

Por meio desse trabalho perscrutado pelo instituto alemão é que "consiste en que por primera vez tendremos una descripción y un análisis exacto de los orígenes, evolución, características, desafíos y destino posible del derecho constitucional en el subcontinente" (ARANGO, 2017, p. 191). É a partir das trocas de experiências entre pesquisadores alemães e latino-americanos que o ius constitucionale commune na América Latina (ICCAL) se apresenta como um projeto jurídico, político e social de um direito latino-americano comum, preocupado com o reestabelecimento da democracia após a superação dos períodos de ditaduras militares vivenciados pela região (ALTERIO, 2018, p. 4).

Nesse contexto, o ius constitucionale commune latino-americano é considerado como um constitucionalismo transformador que atua em âmbito regional. A partir da compreensão 
de que os países que compõem a América Latina ${ }^{3}$ possuem não só uma história semelhante de experiências com governos autoritários e hiperpresidencialistas - como também desafios em comum - como, por exemplo, desigualdade, violência e exclusão social - torna-se ainda mais desejável o desenvolvimento de standards mínimos em matéria de direito constitucional para a região. Diante desses impasses que formam o cenário da América Latina, é perceptível a existência de uma violação sistemática de direitos humanos, a qual impossibilita o progresso e o fortalecimento do Estado de Direito e da democracia. Os referidos institutos decrescem exponencialmente ao passo que os indivíduos fragilizados pela desigualdade e exclusão social não se encontram em mesmo nível de igualdade para integrar as deliberações públicas (MELLO, 2019, p. 256).

Diante dessa realidade, o conceito ius constitucionale commune na América Latina é representado pela busca da efetivação da tríade Estado de Direito, democracia e direitos humanos, buscando a alteração da realidade política e social na América Latina, de forma que "el respeto de los derechos humanos, del principio democrático y del Estado de derecho, son los ejes centrales de un derecho constitucional latinoamericano y pilares del nuevo ius constitutionale commune" (BOGDANDY, 2014, p. 4).

O constitucionalismo transformador incita uma mudança gradual da realidade latinoamericana, concomitante com a integração das ideias de supraestatalidade, ampliação do diálogo entre ordens nacionais e internacionais e a atuação judicial para o desenvolvimento de um ius constitucionale commune na América Latina (MELLO, 2019, p. 257). Do mesmo modo, essa transformação concreta e que ocorre de maneira gradual, para Bogdandy (2015, p. 31), é um "traço distintivo da perspectiva do ICCAL. Ninguém aposta em soluções rápidas ou revolucionárias, e muitos concentram-se no árduo processo necessário para uma jurisprudência transformadora.". Para orientar essas transformações o ius constitucionale commune propicia, além de uma inter-relação entre ordenamentos jurídicos estatais e o direito internacional, orientações para a superação da complexa situação vivenciada na região Latinoamericana, para com isso "estruturar e gerar comunicação e dotar de sentido as construções

\footnotetext{
${ }^{3}$ Alguns países da América Latina não integram o Sistema Interamericano de Proteção e nem reconhecem a competência da Corte Interamericana de Direitos Humanos. Hodiernamente, a Convenção Americana de Direitos Humanos conta com 23 Estados integrantes, e desses 20 reconheceram a competência da Corte Interamericana de Direitos Humanos. Integram ao Sistema Interamericano - até o ano de 2019 - os seguintes países: Argentina, Barbados, Bolívia, Brasil, Chile, Colômbia, Costa Rica, Dominica, El Salvador, Equador, Grenada, Guatemala, Haiti, Honduras, Jamaica, México, Nicarágua, Panamá, Paraguai, Peru, República Dominicana, Suriname e Uruguai. (RAMOS, 2020, n.p)
} 
doutrinárias capazes de converter promessas e garantias em realidade." (BOGDANDY, 2019b, p. 256).

O ICCAL desenvolve standards em relação a temas envolvendo democracia, direitos humanos e Estado de Direito em âmbito regional. Tais temas se desenvolvem com base na Convenção Americana de Direitos Humanos, nas Constituições nacionais, no posicionamento dos órgãos do Sistema Interamericano de Direitos Humanos e no entendimento das Cortes nacionais em relação ao tema discutido (MELLO, 2019, p. 257).

Nessa senda, o enfoque não é a interação a um debate global sobre assuntos abstratos, mas sim tratar de situações reais de violações humanas inadmissíveis e que são o cerne dos déficits sistêmicos que assolam a região. Assim, o ICCAL tem a inclinação prática de fazer ganharem efetividade as promessas reformuladas após a superação de um período sob regência de governos autoritários, sendo elas a busca pela igualdade e democracia previstas nas novas Constituições latino-americanas (BOGDANDY, 2015, p. 28):

\footnotetext{
Trata-se de assegurar, no âmbito regional, a implementação das decisões e o cumprimento das promessas centrais das constituições estatais que se moldaram sobretudo a partir dos compromissos que seguiram os governos autoritários da década de 1970 e 1980. O grande problema é que os ordenamentos jurídicos e as estruturas reais de poder não se ajustaram a essas decisões e promessas constitucionais, ou seja, houve poucas mudanças nesse sentido. Portanto, à luz dessa discussão, não é surpreendente a baixa efetividade das disposições legais voltadas à inclusão com um componente social (BOGDANDY, 2015, p. 26).
}

Assim, a criação de um direito comum latino-americano desencadeia um diálogo entre as Constituições da região, o direito internacional público e os preceitos de direitos humanos (JARAMILLO, 2017, p. 580). Essa interligação entre os sistemas nacionais e internacionais é importante para o aumento no grau de proteção em razão da cooperação entre o âmbito interno e internacional, proporcionando aos direitos humanos uma proteção multinível, assunto esse que se abordará no capítulo seguinte.

\section{Relação entre os ordenamentos jurídicos nacionais e o Sistema Interamericano de Proteção aos Direitos Humanos (SIDH)}

A região da América Latina e do Caribe possui o maior índice de desigualdade no mundo, conforme indica estimativa realizada pela comissão econômica das Nações Unidas o coeficiente Gini é de 0,5 na região (ONU, 2018, <www.nacoesunidas.org>). Segundo o 
International Development Bank, a população do continente latino-americano é integrada em $25 \%$ por residentes afrodescendentes e $8 \%$ da população corresponde a pessoas de origem indígena; ambos os grupos são considerados por indicadores sociais como sendo mais propícios a sofrerem discriminações e violações de direitos, apontando para um crescimento exponencial no quesito vulnerabilidade quando o integrante desses grupos for do sexo feminino, o que ocorre em razão da etnização e feminização da pobreza, que traz a ideia da interseccionalidade que é o reconhecimento de que, por vezes, a discriminação pode ser composta por múltiplas camadas. Os elevados índices de violência - juntamente com a desigualdade - demonstram outro fator que desperta preocupações: dos vinte países com maior índice de homicídios, dez desses situam-se na América Latina; mesmo a região concentrando apenas $9 \%$ da população mundial, ainda perfaz $27 \%$ dos homicídios (PIOVESAN, 2017, p. 1359).

É neste contexto, de uma América Latina fragilizada, que o Sistema Interamericano de Direitos Humanos é visto como um mecanismo essencial para a efetiva proteção dos direitos humanos, nos casos em que o sistema interno deixa de prestar ou presta de maneira insuficiente os direitos a seus tutelados. Sendo assim, "com a atuação da sociedade civil, a partir de articuladas e competentes estratégias de litigância, o sistema interamericano tem a força catalizadora de promover avanços no regime de direitos humanos" (PIOVESAN, 2012, p. 74). Dessa forma, o diálogo jurisdicional ${ }^{4}$ possibilita o fortalecimento do sistema multinível de proteção aos direitos humanos, propiciando consequente ganho de influência ao Sistema Interamericano (PIOVESAN, 2014, p. 89).

Contudo, alterou-se a visão que anteriormente se tinha de que o centro do poder público era compreendido como sendo unicamente o Estado. Atualmente, instituições supranacionais e internacionais guardam elevada influência em relação à convivência social e ao exercício do poder público dos Estados, tanto na Europa quanto na América Latina (BOGDANDY, 2014, p. 5).

Para Resende (2019, p. 60), atualmente não só o Estado-Nação é dotado de autoridade política e normativa; essa descentralização desencadeia uma alteração no ordenamento jurídico global, o que reflete também na inter-relação entre direito nacional e o ordenamento jurídico internacional. Esse fenômeno se deve à globalização, já que é através dela que se desenvolveram "conexões formais e informais entre diversos atores e instituições,

\footnotetext{
${ }^{4} \mathrm{O}$ diálogo jurisdicional abarca quatro modalidades: diálogos travados com o sistema global, sistemas regionais, com os sistemas nacionais e com a sociedade civil. (PIOVESAN, 2014, p. 89) 
tornando opaca e incerta a distinção daquilo que é nacional e o que é internacional" (RESENDE, 2019, p. 60).

Essas interconexões na América Latina são possíveis graças às cláusulas de abertura presentes nas constituições nacionais latino-americanas, da integração dos Estados ao Sistema Interamericana e ao reconhecimento da jurisdição da Corte Interamericana de Direitos Humanos pelos Estados-partes. Esses diálogos entre cortes nacionais e internacionais "é caracterizado pelo fenômeno do 'controle de convencionalidade', na sua forma difusa e concentrada" (PIOVESAN, 2014, p. 92).

Diante desse cenário de recrudescimento do Direito Internacional, emergiram diversos debates quanto à forma de solucionar eventuais colisões entre os sistemas jurídicos internos e internacionais e como poderiam ser resolvidos possíveis conflitos hierárquicos entre essas normas. Para responder a esses anseios, surgiram teorias a fim de deslindar a relação travada entre esses dois ordenamentos. Assim, desenvolveram-se as teorias monista e dualista, que por muito tempo foram utilizadas pelos teóricos para solucionar esses conflitos. A primeira teoria (monista), proclama existir uma correlação e hierarquia entre $o$ ordenamento jurídico interno e o internacional. A segunda teoria (dualista), inversamente da primeira, sustenta a total separação desses ordenamentos jurídicos, afirmando a completa independência entre sistema interno e internacional (CALIXTO; CARVALHO, 2016, n. p).

Assim, diante da relativização do conceito de soberania absoluta dos Estados que, segundo Leal e Brugger (2007, p. 124) decorre da transformação das constituições modernas que "transformaram a soberania irrestrita de um governo sem limites em uma soberania e um poder limitados, visando a garantir uma vida pacífica e segura para cada cidadão que vive naquele Estado.", abre-se espaço ao entendimento de que o direito deve ser compreendido como um todo, adotando o senso de prevalência da norma que de maneira mais eficaz e ampla irá propiciar a proteção do ser humano, independentemente da ordem instituidora dessa norma, seja ela proveniente do direito doméstico ou do direito internacional (CALIXTO; CARVALHO, 2016).

Sob essa perspectiva de diálogo entre cortes, vale ressaltar as doutrinas do transconstitucionalismo e do interconstitucionalismo. A segunda exterioriza-se pela urgência “de enquadrar o fenómeno da interação reflexiva entre normas constitucionais de distintas fontes que convivem no mesmo espaço político - aquele da União Europeia - o que implica a atuação em rede para a solução de problemas constitucionais", de maneira que a teoria da interconstitucionalidade é conformada pela pluralidade de fontes, a qual traz a ideia de uma interconexão em rede, organizando-se sem haver uma hierarquia (SILVEIRA, 2015, p. 23- 
24). Já a teoria do transconstitucionalismo engloba "A interação entre ordens jurídicas vai além do mero diálogo entre Cortes, isso muito devido ao fato de que os problemas enfrentados podem necessitar de um diálogo entre instâncias nacionais, internacionais, supranacionais, tanto quanto instâncias locais nativas." (HARDMAN, 2018, p. 112-113).

Assim, as clássicas teorias monista e dualista não foram capazes de abarcar os novos desafios, sendo que, hodiernamente, a teoria do Pluralismo Constitucional ${ }^{5}$ é a que mais adequadamente instiga a reflexão sobre a relação posta entre as constituições domésticas e os tratados internacionais que formam o Sistema Interamericano de Direitos. A teoria é calcada no entrelaçamento horizontal entre o ordenamento jurídico internacional e nacional, onde a ideia de hierarquia é substituída pela heterarquia, a qual preconiza ideais de mútua colaboração, sem haver qualquer tipo de subordinação entre essas ordens jurídicas (RESENDE, 2019, p. 65):

O pluralismo constitucional molda a relação entre ordenamentos jurídicos em termos de diálogo, de cooperação e de heterarquia constitucional. A heterarquia reclama, por sua vez, que a interação entre as ordens jurídicas, nacional e internacional, deva ser dirigida à realização de valores e princípios constitucionais comuns, especialmente a proteção dos direitos humanos. (RESENDE, 2019, p. 71)

Essa heterarquia, ou em outras palavras, a ausência de hierarquia, permite concluir que tanto o ordenamento jurídico doméstico como o internacional - mais especificamente o Sistema Interamericano de Direitos Humanos - são diferentes, porém são “interconectados e interdependentes, que se relacionam, institucional, normativa e jurisdicionalmente, de forma horizontal, sem critério de superioridade", pois ambos agem no intuito de promover a proteção dos seres humanos e seus direitos (RESENDE, 2019, p. 71).

Esse relacionamento direto entre ordem nacional e sistema internacional decorre principalmente das transformações constitucionais decorrentes do período pós II Guerra Mundial, onde as atrocidades cometidas nesse período serviram para recrudescer a noção de democracia e direitos humanos, fazendo com que os direitos fundamentais se tornassem elementos centrais das Constituições, o que, por sua vez, acaba dando espaço para a incorporação de direitos previstos na ordem internacional (LEAL, 2007, p. 51).

É graças a essas transformações constitucionais que "se comprueba uma permeabilidad policéntrica y a múltiples velocidades del fenómeno de internacionalización,

\footnotetext{
${ }^{5}$ Segundo Magalhães (2015, p. 71-72), o precursor na defesa da ideia de um pluralismo constitucional é Neil Mac Cormick, sendo posteriormente seguido por Neil Walker. 
que evidencia un pluralismo dialógico entre el derecho internacional, supranacional y doméstico" (ANTONIAZZI, p. 418). A característica de abertura possibilita, além de uma integração entre o direito doméstico e internacional, a expansão do bloco de constitucionalidade, principalmente na área dos direitos humanos. Assim, não só ocorre uma constitucionalização do Direito Internacional, como também um processo de internacionalização do Direito Constitucional (PIOVESAN, 2012, p. 69).

Atualmente, os tratados internacionais de direitos humanos - e, mais especificamente, no cenário interamericano, a Convenção Americana sobre Direitos Humanos, juntamente com o Protocolo de San Salvador e as sentenças da Corte Interamericana - são instrumentos capazes de criar essa interlocução entre diferentes ordenamentos jurídicos, que possibilitam que esses atores, de maneira conjunta com o ordenamento jurídico interno, acabem suprindo suas insuficiências e influenciando uns aos outros com o intuito de beneficiar o ser humano (RESENDE, 2019, p. 75).

Tendo em vista que a diversidade é uma marca característica da América Latina, o que por sua vez ocasiona um pluralismo constitucional na região, ao analisar essa interrelação desses sistemas "o Ius Commune se afasta de uma proposta unificadora para se voltar a um processo de harmonização capaz de compatibilizar, de um lado, a fixação de standards mínimos comuns em direitos humanos, e de outro, respeito à diversidade." (OLSEN; KOZICKI, 2019, p. 305). Assim, possibilita-se pensar em um "direito constitucional comum interamericano ou, dito de outra forma, em um Ius Constitutionale Commune nas Américas, que se fortalece com o diálogo jurisdicional decorrente da interconexão dos sistemas jurídicos" (RESENDE, 2019, p. 77).

Desta maneira, o direito comum latino-americano é vislumbrado como a interconexão de sistemas jurídicos diferentes, mas que possuem o mesmo objetivo, a proteção dos direitos humanos. E, para isso, "el paradigma del constitucionalismo trasformador muestra tendencias hacia la consolidación de un acervo común de estándares que salvaguardan los derechos, la democracia y el Estado de derecho" (ANTONIAZZI, p. 418). Com isso, o ius commune latino-americano compreende normas que almejam a mesma finalidade, podendo elas ser tanto internacionais - como por exemplo a Convenção Americana de Direitos Humanos - como nacionais, podendo-se citar como exemplo de normas nacionais integradoras as cláusulas de abertura e as cláusulas interpretativas, responsáveis pelo reconhecimento do dever de interpretação dos direitos fundamentais conforme os compromissos firmados pelos países quando ratificam esses instrumentos internacionais (BOGDANDY, 2014, p. 18-19). 
Dessa forma, para que o ICCAL possa desenvolver o constitucionalismo transformador com o qual se comprometeu, respeitando a pluralidade jurídica e ao mesmo tempo conformando padrões comuns para a região, confia-se ao diálogo entre os Estados e o Sistema Interamericano de proteção dos direitos humanos, uma "fertilização cruzada" capaz de desenvolver standards sobre a temática dos direitos (OLSEN; KOZICKI, 2019, p. 309). Assim, o pluralismo dialógico "é tanto um objetivo do ICCAL, quanto um meio para alcançálo" (BOGDANDY, 2019b, p. 272), sendo que esses diálogos jurisdicionais não ficam restritos apenas à "contínua troca de argumentos entre duas Cortes, mas também na influência da decisão de uma Corte nos fundamentos de outra, ou mesmo na rejeição fundamentada dos argumentos estrangeiros" (OLSEN; KOZICKI, 2019, p. 311).

Diante da relevância do Sistema interamericano para atingir esses padrões mínimos e ampliar a proteção dos direitos humanos, e mais especificamente, dada a importância das decisões emitidas pela Corte IDH para alcançar essa finalidade, passa-se, na sequência, a tratar sobre o desenvolvimento da teoria do ius constitucionale commune no âmbito da jurisprudência da Corte IDH, a partir da análise dos casos contenciosos em que se faz menção ao instituto.

\section{A conformação do ius constitucionale commune na jurisprudência da Corte} Interamericana de Direitos Humanos

O cerne do ius constitucionale commune, bem como seus primeiros passos rumo a sua formação na América Latina, centraliza-se na doutrina do controle de convencionalidade. Foi no julgamento do caso Almonacid Arellano vs. Chile, em 26 de setembro de 2006, que pela primeira vez a Corte Interamericana de Direitos Humanos conceituou o controle de convencionalidade ${ }^{6}$ no parágrafo 124 da decisão.

124. La Corte es consciente que los jueces y tribunales internos están sujetos al imperio de la ley y, por ello, están obligados a aplicar las disposiciones vigentes en el ordenamiento jurídico. Pero cuando un Estado ha ratificado un tratado internacional como la Convención Americana, sus jueces, como parte del aparato del Estado, también están sometidos a ella, lo que les obliga a velar porque los efectos de las disposiciones de la Convención no se vean mermadas por la aplicación de leyes contrarias a su objeto y fin, y que

\footnotetext{
${ }^{6}$ Anteriormente, em 2003, no caso Myrna Mack Chang vs. Guatemala, o controle de convencionalidade foi mencionado, porém tratando-se exclusivamente do controle concentrado de convencionalidade, desenvolvido apenas no âmbito da própria Corte IDH. Já a ideia de controle difuso de convencionalidade, exercido internamente pelas jurisdições dos Estados, foi explorada apenas no caso Almonacid Arellano vs. Chile, no ano de 2006. (LATORRE, 2018, p. 2-3)
} 
desde un inicio carecen de efectos jurídicos. En otras palabras, el Poder Judicial debe ejercer una especie de "control de convencionalidad" entre las normas jurídicas internas que aplican en los casos concretos y la Convención Americana sobre Derechos Humanos. En esta tarea, el Poder Judicial debe tener en cuenta no solamente el tratado, sino también la interpretación que del mismo ha hecho la Corte Interamericana, intérprete última de la Convención Americana. (CORTE INTERAMERICANA DE DIREITOS HUMANOS, 2006, p. 53)

Assim, a Corte manifesta entendimento no sentido de que, quando os Estados se comprometem com um tratado internacional - como é o caso da Convenção Americana de Direitos Humanos - não só se submetem aos compromissos elencados no Tratado, mas também os seus juízes internos, por conformarem parte do Estado, têm a obrigação de seguir o disposto na Convenção e garantir que sua aplicação não seja desvirtuada ou amenizada por leis contrárias aos seus objetivos (CORTE INTERAMERICANA DE DIREITOS HUMANOS, 2006, p. 53). Fixou-se, com isso, uma noção de exercício interno de um controle difuso de convencionalidade das leis em relação aos dispostos na Convenção Americana de Direitos Humanos, tarefa na qual o Poder Judiciário "debe tener en cuenta no solamente el tratado, sino también la interpretación que del mismo ha hecho la Corte Interamericana, intérprete última de la Convención Americana" (CORTE INTERAMERICANA DE DIREITOS HUMANOS, 2006, p. 53).

Assim, na decisão do Caso Almonacid Arellano vs. Chile, a Corte Interamericana preconizou que o controle de convencionalidade - para que seja devidamente executado incumbe aos juízes que não apenas atentem para os conteúdos positivados na Convenção Americana, como também nas legítimas interpretações proferidas pela Corte, devido ao seu caráter vinculante e da eficácia "erga omnes" da "res interpretata", sendo que, no âmbito interno dos Estados, o controle de convencionalidade é constituído pelo auto-reconhecimento dos juízes nacionais como juízes interamericanos incumbidos de "garantizar los atributos de los derechos contenidos en la $\mathrm{CADH}$, impidiendo que éstos sean afectados por normas jurídicas de derecho interno o conductas y actos de agentes del Estado que desconozcan los estándares mínimos determinados convencionalmente" (ALCALÁ, 2012, p. 60-61).

Desse modo, fortaleceu-se o posicionamento da Corte IDH no sentido de que o controle de convencionalidade deve ser realizado igualmente pelas jurisdições nacionais, objetivando desopilar a Corte Interamericana de Direitos Humanos, não proporcionando um acúmulo desnecessário de casos na jurisdição da Corte quando, acertadamente, poderiam ser solucionados pela atuação de juízes nacionais, esses resolvendo os casos através da aplicação 
da Convenção Americana e das interpretações e aplicações anteriormente realizadas pela Corte (ALCALÁ, 2013, p. 62-63).

Outro aspecto que corrobora esse posicionamento pode ser encontrado no julgamento do Caso Cabrera García e Montiel Flores vs. México, de 26 de novembro de 2010, no qual a Corte Interamericana Direitos Humanos ressaltou que a incorporação da doutrina do controle de convencionalidade emergiu do processo de internacionalização, tendo influenciado as mais altas Cortes dos Estados ${ }^{7}$ em seguir os preceitos estipulados pela Corte IDH:

\begin{abstract}
Resulta evidente que la Corte IDH crea la doctrina del "control difuso de convencionalidad" advirtiendo la tendencia de la "constitucionalización" o, si se prefiere, "nacionalización" del "derecho internacional de los derechos humanos" y particularmente la aceptación de su jurisprudencia convencional como elemento "hermenéutico" y de "control" de la normatividad interna por parte de los propios tribunales internos; es decir, la Corte IDH recibió el influjo de la práctica jurisprudencial de los jueces nacionales para crear la nueva doctrina sobre el "control difuso de convencionalidad (CORTE INTERAMERICANA DE DIREITOS HUMANOS, 2010, p. 11).
\end{abstract}

A decisão ainda faz menção, ainda, ao Caso Almonacid Arellano vs. Chile, rememorando que, desde o seu julgamento, em 2006, a Corte passou a manifestar-se no sentido de irradiar seus entendimentos jurisprudenciais, com o escopo de obter uma receptividade dos standards internacionais por parte dos Estados signatários da Convenção Americana, desencadeando uma maior "intensidad y profundidad de la "nacionalización" o "constitucionalización" del Derecho Internacional de los Derechos Humanos, como lo demuestra la recepción de dicha doctrina por las altas jurisdicciones nacionales" (CORTE INTERMERICANA DE DIREITOS HUMANOS, 2010, p. 32).

Na decisão do Caso Cabrera García e Montiel Flores vs. México, não só o controle de convencionalidade é reafirmado, como também vislumbra-se, pela primeira vez, a menção da Corte Interamericana de Direitos Humanos menciona o termo ius constitucionale commune, presente nos parágrafos 85 a 88 das razões do voto do juiz ad hoc Eduardo Ferrer Mac-Gregor, visto como "algunas conclusiones generales sobre la trascendencia de esta fundamental doctrina de la Corte IDH, que de manera progresiva está creando un ius constitutionale commune en materia de derechos humanos para el continente americano"

\footnotetext{
${ }^{7}$ Mencionou o juiz interamericano Eduardo Ferrer Mac-Gregor Poisot, no parágrafo 30 da fundamentação do voto, que outros Estados partes da Convenção Americana de Direitos Humanos adotaram a jurisprudência da Corte IDH no sentido de reconhecer e exercer o controle difuso de convencionalidade, construído na ocasião do julgamento do Caso Almonacid Arellano vs. Chile em 2006, citando a título de exemplo o influente precedente fixado pela Suprema Corte Argentina no caso Mazzeo, Lulio Lilo y otros vs. Argentina no ano de 2007. (CORTE INTERAMERICANA DE DIREITOS HUMANOS, 2010, p. 11-12)
} 
(CORTE INTERAMERICANA DE DIREITO HUMANOS, 2010, p. 01). Destarte, o desenvolvimento do ius constitucionale commune na América Latina é mencionado da seguinte maneira no parágrafo 88 do voto do juiz ad hoc Eduardo Ferrer Mac-Gregor:

88. En definitiva, la trascendencia de la nueva doctrina sobre el "control difuso de convencionalidad" es de tal magnitud, que probablemente en ella descanse el futuro del Sistema Interamericano de Protección de los Derechos Humanos y, a su vez, contribuirá al desarrollo constitucional y democrático de los Estados nacionales de la región. La construcción de un auténtico "diálogo jurisprudencial" entre los jueces nacionales y los interamericanos seguramente se convertirá en el nuevo referente jurisdiccional para la efectividad de los derechos humanos en el siglo XXI. Ahí descansa el porvenir: en un punto de convergencia en materia de derechos humanos para establecer un auténtico ius constitutionale commune en las Américas (CORTE INTERAMERICANA DE DIREITOS HUMANOS, 2010, p. 3233, grifo nosso).

Contudo, mencionou o juiz Eduardo Ferrer Mac-Gregor, no parágrafo 87 do fundamento do seu voto, que nesse caso não busca definir a qual orgão imcumbe a última palavra, "sino fomentar el diálogo jurisprudencial creativo, responsable y comprometido con la efectividad de los derechos fundamentales. Los jueces nacionales ahora se convierten en los primeros jueces interamericanos" (CORTE INTERAMERICANA DE DIREITOS HUMANOS, 2010, p. 32). Com isso, buscou-se afirmar que os juízes internos dos Estados são os principais responsáveis por alinhar a legislação nacional de acordo com os padrões internacionais, devendo assim a Corte Interamericana de Direitos Humanos garantir isso e “tener plena consciencia de los estándares que irá construyendo en su jurisprudencia, teniendo en consideración, además, el 'margen de apreciación nacional' que deben contar los Estados nacionales para interpretar el corpus juris interamericano" (CORTE INTERAMERICANA DE DIREITOS HUMANOS, 2010, p. 32).

No mesmo sentido, de reforço ao ius constitucionale commune latino-americano, a Corte Interamericana de Direitos Humanos, em 31 de agosto de 2017, reconheceu, pela primeira vez, na decisão do Caso Lagos del Campo vs. Perú, a possibilidade de judicialização do artigo 26 da Convenção Americana sobre Direitos Humanos. A situação que ensejou tal manifestação da Corte envolvia a demissão do senhor Alfredo Lagos del Campo, a qual ocorreu em razão de uma manifestação feita por ele em uma entrevista enquanto exercia a função de presidente do Comitê Eleitoral da Comunidade Industrial da Empresa Ceper-Pirelli, na qual ele denunciou o emprego de atos coercitivos por parte do Conselho de Administração da Companhia a fim de fraudar as eleições do Comitê Eleitoral, coadunando assim uma 
interferência indevida sob as organizações representativas dos empregados e no devido andamento das referidas eleições (CORTE INTERAMERICANA DE DIREITOS HUMANOS, 2017. p. 04)

Assim, interpretando o artigo 26 da Convenção Americana, em relação aos direitos laborais de Alfredo Lagos del Campo, a Corte reconheceu serem estes direitos trabalhistas integrantes da proteção elencada no mencionado artigo da Convenção, derivando os direitos trabalhistas das normas sobre direitos econômicos, sociais e educacionais, ciência e cultura através da leitura conjunta dos artigos $45 . \mathrm{b}$ e c, 46 e 34.g da Carta da Organização dos Estados Americanos (CORTE INTERAMERICANA DE DIREITOS HUMANOS, 2017. p. 03). Com isso, percebe-se um notável progresso em relação a proteção dos direitos trabalhistas e dos direitos econômicos, sociais, culturais e ambientais, assim, influenciando a decisão na formação de uma nova jurisprudência interamericana (ANTONIAZZI et al., 2018, p. 16).

Nessa decisão, igualmente como na ocasião do julgamento do Caso Cabrera García e Montiel Flores vs. México, contou-se com a contribuição do juiz Eduardo Ferrer Mac-Gregor Poisot, que, no parágrafo 50 da fundamentação de seu voto, explanou a relevância do caso para a construção de uma jurisprudência protetiva dos direitos economicos, sociais, culturais, ambientais, civis e políticos, conforme segue o teor do voto proferido:

Así, los avances realizados en el caso Lagos del Campo en materia del derecho al trabajo (estabilidad y asociación laboral), y en materia de la protección y garantía de los DESCA por la vía directa y mediante un análisis integral y conglobado de los derechos (económicos, sociales, culturales, ambientales, civiles y políticos), permiten dar un paso histórico hacia una nueva época de la jurisprudencia interamericana (CORTE INTERAMERICANA DE DIREITOS HUMANOS, 2017, p. 18).

Contudo, ainda ressaltou, no artigo 3 das razões de seu voto, que a Corte Interamericana de Direitos Humanos - superando sua jurisprudência anterior e valendo-se da interpretação evolutiva - ressignificou o disposto no artigo 26 da Convenção Americana, abandonando o antigo caráter de mera norma programática para tornar-se um artigo que vincula "este Tribunal Interamericano la obligación de remitirse a la Carta de la Organización de Estados Americanos [...] para lograr la plena efectividad de los derechos que se derivende las normas económicas, sociales y sobre educación, ciencia y cultura contenidas en dicha Carta” (CORTE INTERAMERICANA DE DIREITOS HUMANOS, 2017, p. 2). 
Desse modo, da decisão do Caso Lagos del Campo, decorreu a alteração de posicionamento da jurisprudência da Corte Interamericana de Direitos Humanos onde reconhece a judiciabilidade direta dos direitos econômicos, sociais, culturais e ambientais, sendo considerada como "el marco de la inclusión como pilar fundamental del ius constitutionale commune en América Latina (ICCAL) y bajo el enfoque del constitucionalismo transformador" (ANTONIAZZI et al., 2018, p. 15). Identifica-se, no caso sob comento, três claras barreiras - dentre tantas outras possíveis de se verificar - que o ICCAL enfrenta no desenvolvimento de sua construção, identificadas por Flávia Piovesan (2014, p. 96-100) como “i) fomentar uma cultura jurídica inspirada em novos paradigmas jurídicos e na emergência de um novo Direito Público; ii) fortalecer o sistema interamericano de proteção de direitos humanos; iii) avançar na proteção dos direitos humanos, da democracia e do estado de direito".

Juntamente ao controle de convencionalidade, há outros institutos que podem ser elencados como conformadores de uma uniformização da jurisprudência interamericana e, portanto, fortalecedores do ius constitucionale commune na América Latina. Utilizando-se da doutrina de Mac-Gregor (2013, p. 270), como citado anteriormente, pode-se mencionar como exemplo a eficácia vinculante e "erga omnes" dos standards interpretativos (res interpretata) advindos das decisões proferidas pela Corte Interamericana de Direitos Humanos em casos concretos, onde os efeitos da sentença irradiam-se a todos os Estados-partes.

En ese sentido "por el solo hecho de ser parte en la Convención Americana, toda autoridad pública y todos sus órganos, incluidas las instancias democráticas, jueces y demás órganos vinculados a la administración de justicia en todos los niveles, están obligados por el tratado, por lo cual deben ejercer, en el marco de sus respectivas competencias y de las regulaciones procesales correspondientes, un control de convencionalidad tanto en la emisión y aplicación de normas, en cuanto a su validez y compatibilidad con la Convención, como en la determinación, juzgamiento y resolución de situaciones particulares y casos concretos, teniendo en cuenta el propio tratado $\mathrm{y}$, según corresponda, los precedentes o lineamientos jurisprudenciales de la Corte Interamericana".(MAC-GREGOR, 2013, p. 670-671)

Com isso, reafirmando a ideia de que o controle de convencionalidade deve ser exercido não apenas em âmbito concentrado, pela Corte Interamericana de Direitos Humanos, como também ex officio pelos órgãos que compõe o Estado ${ }^{8}$ estando esses "obligados por el

\footnotetext{
${ }^{8}$ Diante ao influxo entre as ordens nacionais e o Sistema Interamericano há por parte da Corte Interamericana de Direitos Humanos uma postura de deferência em relação a margem de apreciação interna dos Estados, porém, não se pode negar que o seu reconhecimento por meio da jurisprudência interamericana é singelo, 
tratado, lo cual les obliga a ejercer ex officio un control de convencionalidad, teniendo en cuenta el propio tratado y la interpretación que del mismo ha realizado la Corte Interamericana" (MAC-GREGOR, 2013, p. 689).

Menciona-se ainda o fato de que a Corte Interamericana de Direitos Humanos igualmente promove o ius constitucionale commune por meio da adoção de sentenças com caráter estruturante. $\mathrm{O}$ teor dessas decisões vai além da mera condenação do Estado na reparação das partes afetadas por violações, as sentenças estruturantes caminham no sentido de instigar alterações estruturais e preventivas ao acontecimento de novas violações através da previsão de medidas de não-repetição em suas decisões (LEAL; ALVES, 2015, p. 288).

Contudo, a região latino-americana aparenta caminhar rumo ao ius commune, onde cada vez mais os Estados buscam dialogar com o Sistema Interamericano e alinhar suas decisões internas com os padrões interpretativos jurisprudenciais fixados pela Corte Interamericana de Direitos Humanos. Assim, “o direito comum latino-americano dos direitos humanos serve para lidar conjuntamente com os grandes desafios da América Latina." (BOGDANDY, 2019a, p. 241), portanto, mira-se a identificação, compreensão e superação dos défices estruturais capazes de gerar violações inaceitáveis no que tange a dignidade humana e, principalmente, promover os direitos humanos, a democracia e do Estado de direito, para assim fornecer efetiva proteção aos indivíduos integrantes da região Latinoamericana.

\section{Conclusão}

Ao longo do trabalho, buscou-se delimitar a conceituação da teoria do ius constitucionale commune na região latino-americana como conformador de standards interpretativos mínimos para o resguardo dos direitos humanos, os quais reivindicam sua observância por parte de todos os integrantes do Sistema Interamericano. Evidenciando-se que, para tanto, é essencial a interconexão dialógica entre ordenamentos jurídicos nacionais e o Sistema Interamericano para a formação conjunta destes standards em matéria de direitos humanos e a construção de uma rede protetiva cada vez mais ampla sobre a temática na região. De modo que, ao final, passamos a analisar como ocorreu a conformação teórica do ius constitucionale commune no âmbito de atuação contenciosa da Corte Interamericana de Direitos Humanos - e principalmente por meio de sua jurisprudência, visto ser essa intérprete 
legítima da Convenção Americana de Direitos Humanos - quando através do desenvolvimento da teoria do controle difuso de convencionalidade passa a se conformar um constitucionalismo transformador, sendo esse capaz de propiciar um ius commune na América Latina.

Diante do exposto e respondendo ao questionamento proposto, concluiu-se que o ius constitucionale commune conceitua-se como sendo a conformação de padrões protetivos mínimos em matéria de direitos humanos com objetivo de atender aos défices da região latino-americana através do constitucionalismo transformador, atentando-se principalmente para o desenvolvimento da proteção do Estado de Direito, da democracia e dos direitos humanos. Porém, para que essas mudanças ocorram e os standards protetivos sejam definidos e efetivados, há a necessidade do exercício do constitucionalismo transformador, que ocorre principalmente através do diálogo jurisdicional entre cortes nacionais e o Sistema Interamericano de Direitos Humanos.

Já quanto ao surgimento da teoria, pode-se constatar que essa decorre do exercício da jurisdição contenciosa da Corte Interamericana de Direitos Humanos, ao passo que introduz, por meio de suas sentenças estruturantes a projeção de alterações na realidade dos Estados através da fixação de medidas protetivas aos indivíduos e de não-repetição de outras violações. Assim, a sentença interamericana, por intermédio de sua dimensão objetiva e indireta, faz com que sua jurisprudência se torne vinculante a todos os Estados-partes, conformando a eficácia "erga omnes" de suas decisões, o que, juntamente com o exercício do controle difuso de convencionalidade pelos Estados, torna-se o motor propulsor para a conformação de um ius commune interamericano.

\section{Referências}

ALCALÁ, Humberto Nogueira. Diálogo interjurisdiccional, control de convencionalidad y jurisprudencia del Tribunal Constitucional en período 2006-2011. Estudios constitucionales, Chile, n. 2, 2012, p. 57-140.

ALTERIO, Ana Micaela. El Ius Constitutionale Commune Latinoamericanum y los desafíos de la judicialización de la política. Estudios de Filosofía Práctica e Historia de las ideas, Mendoza, v. 20, 2018, p. 01-21.

ANTONIZAZZI, Mariela Morales. Interamericanización como mecanismo del Ius Constitutionale Commune en derechos humanos en América Latina. In: BOGDANDY, A. V. et al (Coord.). Ius Constitutionale Commune en América Latina. Textos básicos para su comprensión. 1 ed., México: Max Planck Institute for Comparative Public Law and International Law, 2017, p. 417-456. 
ANTONIZAZZI, M. M.; MAS-GREGOR, E. F.; PANTOJA, R. F. (Orgs.). Inclusión, Ius Commune y justiciabilidad de los DESCA em la jurisprudencia interamericana EI caso Lagos del Campo y los nuevos desafios. México: Instituto de Estudios Constitucionales del Estado de Querétaro, 2018.

ARANGO, Rodolfo. Fundamentos del Ius Constitutionale Commune en América Latina. In: BOGDANDY, A. V. et al (Coord.). Ius Constitutionale Commune en América Latina. Textos básicos para su comprensión. 1 ed., México: Max Planck Institute for Comparative Public Law and International Law, 2017, p. 179-191.

BAZÁN, Víctor. El control de convencionalidad: incógnitas, desafíos y perspectivas. Justicia constitucional y derechos fundamentales. (s.1.), 2012, p. 17-56.

BOGDANDY, Armin Von. Ius Constitutionale commune latinoamericanum. Una aclaración conceptual. In: BOGDANDY, A. V.; FIX-FIERRO, H.; ANTONIAZZI, M. M. (Coords.). Ius Constitutionale Commune en América Latina: Rasgos, potencialidades y desafios.

México: Inst Max Planck de Derecho Público Comparado y Derecho Internacional; Instituto de Investigaciones Jurídicas, 2014, p. 4-23.

BOGDANDY, Armin Von. Ius Constitutionale Commune na América Latina. Uma reflexão sobre um constitucionalismo transformador. Revista de Direito Administrativo, Rio de Janeiro, v. 269, mai. 2015, p. 13-66. Disponível em:

http://bibliotecadigital.fgv.br/ojs/index.php/rda/article/view/57594. Acesso em: 27 abr. 2020.

BOGDANDY, Armin Von. O mandato transformador do Sistema Interamericano: Legalidade e Legitimidade de um processo jurisgenético extraordinário. Revista Brasileira de Políticas Públicas, Brasília, v. 9, n. 2, ago. 2019ª , p. 231-250. Disponível em: https://www.publicacoesacademicas.uniceub.br/RBPP/issue/view/256. Acesso em: 15 abr. 2020.

BOGDANDY, Armin Von. Ius constitutionale commune na américa latina: um olhar para um constitucionalismo transformador. Revista Culturas Jurídicas, v. 6, n. 14, 2019b, p. 244291.

CALIXTO, A. J.; CARVALHO, L. C. de. Pluralismo jurídico: uma nova perspectiva a respeito da relação entre os sistemas jurídicos internacional e interno. In: XIII Congresso Internacional de Direitos Humanos. 2016, [s.1; s.n]. Disponível em: https://cidhsite.wordpress.com/grupos-de-trabalho-2/apresentacao-oral-gt-7-direitoshumanos-estad -e-fronteiras/. Acesso em: 02 maio 2020.

CORTE INTERMAERICANA DE DIREITOS HUMANOS. Caso Almonacid Arellano y otros vs. Chile: sentencia de 26 de septiembre de 2006 (excepciones preliminares, fondo, reparaciones y costas). San José da Costa Rica, 2006. Disponível em: http://www.corteidh.or.cr/docs/casos/articulos/seriec_154_esp.pdf. Acesso em: 24 jun. 2020.

\section{CORTE INTERAMERICANA DE DIREITOS HUMANOS. Caso Cabrera García e}

Montiel Flores vs. México: sentencia de 26 de noviembre de 2010 (excepciones preliminares, fondo, reparaciones y costas). San José da Costa Rica, 2010. Disponível em: https://www.corteidh.or.cr/docs/casos/articulos/seriec_220_esp.pdf. Acesso em: 24 jun. 2020. 
CORTE INTERAMERICANA DE DIREITOS HUMANOS. Caso Lagos del Campo vs. Perú: sentencia de 21 de agosto de 2017 (excepciones preliminares, fondo, reparaciones y costas). San José da Costa Rica, 2017. Disponível em:

https://www.corteidh.or.cr/docs/casos/articulos/seriec_340_esp.pdf. Acesso em: 26 Jun. 2020.

CORREA, I. Z. N.; FERREIRA, A. F.; NASCIMENTO, L. F. M. Caso Lagos del Campo vs. Peru e seu Duplo Papel Paradigmático na Evolução da Justiciabilidade de Direitos Sociais perante a Corte Interamericana de Direitos Humanos. Prim@ Facie, v. 18, n. 39, 2019, p. 0131. Disponível em: https://periodicos.ufpb.br/index.php/primafacie/article/view/48760. Acesso em: 30 jan. 2020.

FERRER MAC-GREGOR, Eduardo. Eficacia de la sentencia interamericana y la cosa juzgada internacional: vinculación directa hacia las partes (res judicata) e indirecta hacia los estados parte de la convención americana (res interpretata) (sobre el cumplimiento del caso gelman vs. uruguay). Estudios constitucionales, Santiago, v. 11, n. 2, 2013, p. 641-694. Disponível em: https://scielo.conicyt.cl/scielo.php?script=sci_arttext\&pid=S071852002013000200017\&lng=es\&nrm=iso. Acesso em: 19 maio 2020.

HARDMAN, Antônio Ítalo. Controle de convencionalidade e a nova constituição: o interconstitucionalismo à luz do direito interamericano. In: MAIA, Luciano Maris; LIRA, Yulgan (Orgs.). Controle de convencionalidade: temas aprofundados. Salvador: Juspodivm, 2018. p. 209-229.

JARAMILLO, Leonardo García. Desafíos de la interamericanizacion del derecho: la contribución del Ius Constitutionale Commune. In: BOGDANDY, A. V. et al (Coord.). Ius Constitutionale Commune en América Latina. Textos básicos para su comprensión. 1 ed., México: Max Planck Institute for Comparative Public Law and International Law, 2017, p. 577-605.

LATORRE, Edison Ramiro Calahorrano. El Control de convencionalidad como herramienta para el diálogo judicial en lasdecisiones complejas. Anais da $\mathbf{V}$ jornada de direitos fundamentais, Fortaleza, v.1, 2018, p. 1-26. Disponível em: https://www.unifor.br/documents/392178/3142554/Anais+2018+GT+1++Edison+Ramiro+Calahorrano+Latorre.pdf/d1 bf8064-9234-be41-96fa-6202dce00360. Acesso em: 25 jun. 2020.

LEAL, Mônia Clarissa Hennig. Jurisdição constitucional aberta: reflexões sobre a legitimidade e os limites da jurisdição constitucional na ordem democrática. Rio de Janeiro: Lumen Juris, 2007.

LEAL, Mônia Clarissa Hennig; ALVES, Felipe Dalenogare. A corte interamericana de direitos humanos como indutora de políticas públicas estruturantes: o exemplo da educação em direitos humanos - uma análise dos casos Ximenes Lopes e Gomes Lund versus Brasil perspectivas e desafios ao cumprimento das decisões. Revista do Instituto Brasileiro de Direitos Humanos, [S.1.], n. 15, dez. 2015, p. 287-300. Disponível em: http://revista.ibdh.org.br/index.php/ibdh/article/view/318. Acesso em: 03 jul. 2020. 
LEAL, Mônia Clarissa Hennig; BRUGGER, Winfried. Os direitos fundamentais nas modernas constituições: análise comparativa entre as constituições alemã, norte-americana e brasileira. Revista do Direito, ed. 28, 2007, p. 123-142.

LEAL, Mônia Clarissa Hennig; AZEVEDO, Douglas Matheus de. A postura preventiva adotada pela Corte Interamericana de Direitos Humanos: noções de "dever de proteção" do estado como fundamento para a utilização das "sentenças estruturantes". Revista Novos Estudos Jurídicos, n. 2, v. 21, 2016, p. 442-461.

MAGALHÃES, Breno Baía. Pluralismo Constitucional Interamericano: a leitura plural da Constituição de 1988 e o diálogo entre o Supremo Tribunal Federal e a Corte Interamericana de Direitos Humanos. Tese (Doutorado em Direito) - Universidade Federal do Pará, Belém, 2015.

MELLO, Patrícia Perrone Campos. Constitucionalismo, transformação e resiliência democrática no Brasil: o Ius Constitucionale Commune na América Latina tem uma contribuição a oferecer?. Revista Brasileira de Políticas Públicas, Brasília, v. 9, n. 2, ago. 2019, p. 253-284.

ONU. América Latina e Caribe é região mais desigual do mundo, revela comissão da ONU. ONU, [s.1], 07 maio 2018. Disponível em: https://nacoesunidas.org/america-latina-e-caribe-eregiao-mais-desigual-do-mundo-revela-comissao-da-onu/. Acesso em: 07 jun. 2020.

PIOVESAN, Flávia. Direitos Humanos e diálogo entre jurisdições. Revista Brasileira de Direito Constitucional, São Paulo, n. 19, jan./jun. 2012, p. 67-93. Disponível em:

http://www.esdc.com.br/RBDC/RBDC-19/RBDC-19-001-elementos_iniciais.pdf. Acesso em: 05 maio 2020.

PIOVESAN, Flávia. Ius constitutionale commune latino-americano em Direitos Humanos e o Sistema Interamericano: perspectivas e desafios. Revista Direito \& Práxis, Rio de Janeiro, v. 8, n. 2, mar. 2017, p. 1356-1388.

PIOVESAN, Flávia. Sistema interamericano de direitos humanos: impacto transformador, diálogos jurisdicionais e os desafios da reforma. Revista Direitos Emergentes na Sociedade Global, Santa Maria, v. 3, n. 1, jan./jun 2014, p. 76-101. Disponível em: www.ufsm.br/redesg. Acesso em: 25 jun. 2020.

RAMOS, André de Carvalho. Curso de Direitos Humanos. ed. 7. São Paulo: Saraiva, 2020, [s.n]. Disponível

em:https://books.google.com.br/books?id=7bfEDwAAQBAJ\&pg=PT373\&lpg=PT373\&dq=a + conven $\% \mathrm{C} 3 \% \mathrm{~A} 7 \% \mathrm{C} 3 \% \mathrm{~A} 3 \mathrm{o}+$ americana + ainda + vale + para $+\mathrm{a}+$ venezuela\&source $=b 1 \&$ ots $=\mathrm{m}$ NDVHd8gTx\&sig=ACfU3U2hI1HflDZK7OxfXJ4ZDB7UBYV2qg\&hl=pt-

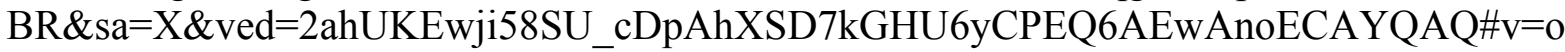
nepage $\& \mathrm{q}=\% 20$ corte $\% 20$ interamericana $\& \mathrm{f}=$ false. Acesso em: 03 maio 2020.

RESENDE, Augusto César Leite de. O futuro do sistema interamericano de direitos humanos é doméstico: diálogo e cooperação entre ordens jurídicas como modelos de empoderamento da corte interamericana de direitos humanos. Tese (Doutorado em Direito) - Pontifícia Universidade Católica do Rio Grande do Sul, Porto Alegre, 2019. Disponível em: http://tede2.pucrs.br/tede2/handle/tede/8527. Acesso em: 02 maio. 2020. 
SARMENTO, Daniel. Direitos fundamentais e relações privadas. Rio de Janeiro. Editora: Lumen Juris, 2004.

SILVEIRA, Alessandra. Interconstitucionalidade: normas constitucionais em rede e integração europeia na sociedade mundial. In: SOLSONA, Gonçal Mayos et. Al. (Orgs.). Interconstitucionalidade e Interdisciplinaridade: desafios, âmbitos e níveis de interação no mundo global. 1 ed. v. 1. Uberlândia: Edição Laboratório Americano de Estudos Constitucionais Comparado - LAECC, 2015, p. 20-84.

Data de recebimento: 01.08.2020

Data de aprovação: 18.10 .2020 